\title{
A Study on Photon Spectrum in Medical Linear Accelerator Based on MCNPX
}

Euntae Park, Dongyeon Lee, Seongjin Ko, Junghoon Kim, Sesik Kang

Department of Radiological Science, College of Health Sciences, Catholic University of Pusan, Korea

\section{$\mathrm{MCNPX}$ 를 이용한 의료용 선형가속장치의 광자 스펙트럼에 관한 연구}

박은태, 이동연, 고성진, 김정훈, 강세식

부산가톨릭대학교 보건과학대학 방사선학과

\begin{abstract}
Medical linear accelerator is used for radiotherapy since it was developed in 1952, the utilization rate is further increased. It is used high energy radiotherapy using the energy of the photon of $6 \mathrm{MeV}$ or more is universal at present, but the creation of the neutron by photonuclear reaction cause a problem that is radiation exposure of patients and operators. Therefore, in this study, to analyze the spectrum of the photon beam of 6 to $24 \mathrm{MV}$ that occurred in the medical linear accelerator using the Monte Carlo code MCNPX, the number of photons of $7.41 \mathrm{MeV}$ or more, which is a neutron production threshold energy of tungsten and average energy. The result of $24 \mathrm{MV}$ in the beginning and the $8 \mathrm{MV}$ was $0.59 \%$ of the total number of detected photons and it was founded that the number of photons are increased which are possible to cause the photonuclear reaction.
\end{abstract}

Key Words : Medical linear accelerator, Photonuclear reaction, MCNPX, Threshold energy

\section{요 약}

의료용 선형가속장치는 1952 년에 개발된 이후 방사선 치료에 사용되어 왔으며 그 활용도가 더욱 증가하고 있다. 현 재는 $6 \mathrm{MeV}$ 이상의 광자 에너지를 사용하는 고 에너지 방사선치료가 보편화되어 사용되고 있으나, 광핵반응에 의한 중성자의 생성으로 환자 및 술자에 대한 피폭이 문제가 되고 있다. 이에 본 연구에서는 MCNPX를 사용하여 의료용 선 형가속장치에서 발생되는 6 24 MV 광자선의 스펙트럼을 분석하고, 평균에너지 및 텅스텐의 중성자 생성 임계에너지 인 $7.41 \mathrm{MeV}$ 이상의 광자 개수를 평가하였다. 그 결과 $8 \mathrm{MV}$ 를 시작으로 $24 \mathrm{MV}$ 에서는 전체 검출 광자 수에 비해 $0.59 \%$ 의 비율로서 광핵 반응을 일으킬 수 있는 광자수가 증가함을 알 수 있었다. 


\section{I . INTRODUCTION}

방사선 치료는 암 치료에 있어서 외과적인 수술과 항암치료와 더불어 중추적인 역할을 하고 있으며, 그 활용도가 더욱 증가하고 있는 추세이다. 방사선치료에 서 사용되는 의료용 선형가속장치는 종양 조직에 방 사선 빔을 집속시킴으로써 종양에는 방사선량을 높이 고, 주위 정상조직에는 방사선량을 최소화하는 방식을 사용한다. 최근에는 과학기술의 발전과 함께 선형가속 장치도 비약적인 발전을 하였으며, 대표적으로 고에너 지화를 들 수가 있다. 고에너지 광자선은 표면선량은 적고, 심부 도달력은 크므로 심부성 병소의 치료에 적 합하며, 용적선량이 적음으로 인해 방사선치료로 인한 부작용이나 방사선 숙취현상도 감소되는 장점을 가진 다 ${ }^{[1]}$.

하지만 일반적으로 $8 \mathrm{MeV}$ 이상의 광자 에너지를 사용하는 경우에는, 치료빔 내에서 광핵 반응 (photonuclear reaction)에 의한 중성자 오염을 수반하게 된다 ${ }^{[2]}$. 물론 중성자 이외에도 소량의 양성자, 알파입 자 같은 이차입자도 방출이 되지만, 방사선 차폐의 관 점에서 바라보면 투과력이 가장 큰 중성자의 영향을 간과해서는 안된다. 선형가속장치의 광핵반응은 타깃 (target), 1 차 조리개(primary collimator), 평탄 여과판 (flattening filter), 2 차 조리개, 다엽 콜리메이터(Multi leaf collimator, MLC) 등의 치료장치 헤드의 구성품들에 의 한 것으로 알려져 있다 ${ }^{[3]}$.

NCRP report 79에서는 이런 치료장치로부터 방출되 는 중성자 발생의 광자 임계 에너지에 대해서, 알루미 늄 $13.06 \mathrm{MeV}$, 철 $13.38 \mathrm{MeV}$, 금 $8.06 \mathrm{MeV}$, 텅스텐 7.41 $\mathrm{MeV}$ 로 보고하였다. 이중 텅스텐은 납보다 차폐능이 우수하여 임상의 고에너지 영역의 X-ray 차폐에 효과 적이며 ${ }^{[4]}$ 또한 타깃, 콜리메이터, MLC 등 치료 헤드의 구성물질로서 가장 많이 사용되고 있다. 텅스텐의 광 자 임계에너지가 $7.41 \mathrm{MeV}$ 임을 감안하면 그 이상의 에너지에서 중성자의 발생은 예견된 것이다. 그럼에도 불구하고 중성자는 광자 외에도 다른 이차입자와의 분리가 어려우며, 중성자 자체의 에너지가 연속적으로 분포하므로 임상에서의 실측은 사실상 쉬운 일이 아 니다.
이에 본 연구에서는 MCNPX를 사용하여 중성자 연 구의 선행자료로서 활용하기 위해, 실제 임상에서 상 용되는 6 24 MV 영역의 광자선에 대한 에너지 스펙 트럼을 추출하였다. 그리고 연속 스펙트럼을 갖는 광 자선에 대하여 에너지대 별로 분석을 함으로써, 평균 에너지와 실제 광핵반응을 일으킬 수 있는 $7.41 \mathrm{MeV}$ 이상의 에너지를 가지는 광자 수에 대하여 조사하였 다.

\section{RESEACH METHOD}

\section{MCNPX(Monte carlo N-particle)}

MCNPX 코드는 몬테칼로 방식을 이용한 계산코드 중 하나로서 미국의 핵무기 연구소인 LANL(Los Alamos National Laboratory)에서 개발한 프로그램이다. 다양한 기하학적 구조를 지원함과 동시에 전자, 광자, 중성자, 양성자 등 다중 입자의 수송이 가능하여 입자 레벨에서 통계의 누적을 통해서 실측이 어려운 상황 을 대체하여 계산을 수행할 수 있다. 또한 Tally(출력 연산자)를 사용하여 플루언스, 에너지 분포, 에너지 흡 수 등 다양한 물리량을 출력할 수 있다. 일반적으로 알려진 단점으로는 확률적 오차를 믿을 만한 범위까 지 줄이기 위해서 많은 전산 시간이 소요된다는 점이 있지만, 이 코드는 윈도우(Windows) 운영체제를 사용 하는 개인용 컴퓨터에서 실행 가능하므로 접근성에 있어서 타 프로그램보다 우위에 있다는 장점을 가진 다 ${ }^{[5],[6]}$.

방사선 치료분야에서도 직접적인 계측의 한계가 있 는 경우에 방사선의 물리적 과정을 통계적 계산법으 로 전산모사하는 몬테카를로 방법이 자주 이용되어 왔다 ${ }^{[7],[8]}$. 의료용 선형가속기에서 방출되는 광자선과 전자선의 물리적 특성은 치료기 헤드의 구성 부품에 의한 의존도가 높다는 선행연구가 많이 발표되었는데, 대부분 EGS4, GEANT4 등의 몬테카를로 시뮬레이션 프로그램을 이용하여 연구 되었담],[10],[11]. 그러나 현 재에는 방사선 치료계획의 수립과 검증, 선량 측정 등 임상의 전반적인 부분에 있어서 $\mathrm{MCNP}$ 의 활용이 증가 하고 있다. 


\section{2. 선형가속장치 헤드 구성}

본 연구에서 사용된 선형가속기는 임상에서 주로 상용되는 일반적인 구성과 형태를 기초로 하여 모사 하였으며, 광자선 모드에 대한 치료기 헤드의 모사구 조는 Fig. 1과 같다.

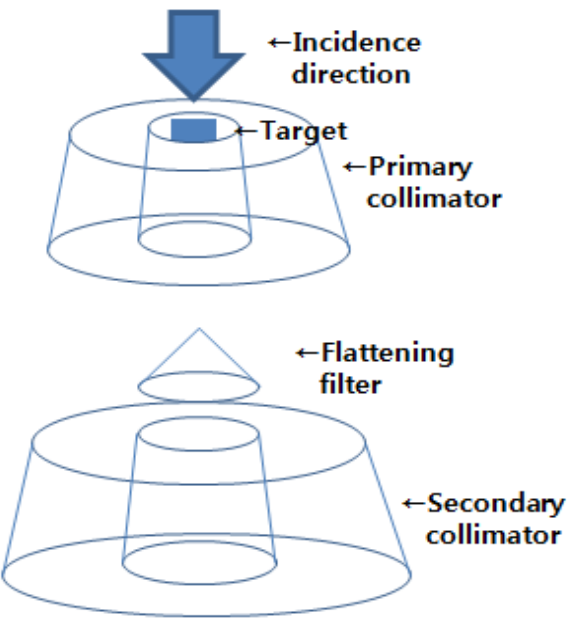

Fig. 1. Schematic representation of the linear accelerator head.

Target의 경우 텅스텐과 구리의 합금으로서 두께 0.8 $\mathrm{cm}$, 반경 $2 \mathrm{~cm}$ 으로 설정하였다. 세부적으로 가속관을 통과한 전자선이 제동복사에 의해 광자가 형성되는 텅스텐(W)은 밀도 $19.4 \mathrm{~g} / \mathrm{cm}^{3}$ 이며 함량비는 ${ }^{182} \mathrm{~W}$ $26.62 \%,{ }^{183} \mathrm{~W} 14.31 \%,{ }^{184} \mathrm{~W} 30.64 \%,{ }^{186} \mathrm{~W} 28.43 \%$ 로 구성 되었다. 제동복사 과정에서 발생되는 고열의 분산을 위한 구리 $(\mathrm{Cu})$ 는 밀도를 $8.94 \mathrm{~g} / \mathrm{cm}^{3}$ 로 하였으며, ${ }^{63} \mathrm{Cu}$ $69.15 \%,{ }^{65} \mathrm{Cu} \quad 30.85 \%$ 로 구성을 하였다. 다음으로 primary collimator의 두께는 $5 \mathrm{~cm}$, 높이는 $12 \mathrm{~cm}$ 로 가운 데가 뚫려있는 원기둥 형태로 모사하였으며, 텅스텐으 로 이루어져 있다. Flattening filter의 두께는 $2.5 \mathrm{~cm}$, 반 경을 $3 \mathrm{~cm}$ 로 설정하였으며 구리로 구성되었다. 이후 조사야를 결정해주는 secondary collimator (JAWS)는 텅 스텐으로 이루어지며 밀도는 $19.4 \mathrm{~g} / \mathrm{cm}^{3}$ 이고, 두께는 $7.8 \mathrm{~cm}$ 로 모사하였다. MLC도 텅스텐으로 구성되며 두 께는 $6.5 \mathrm{~cm}$ 로 설정하였다.

1차적으로 타깃에 부딪혀 광자선을 생성시키게 되
는 전자선의 경우 본 연구에서는 빔의 기준이 되는 중 심축에 대한 에너지 스펙트럼과 방출 광자 개수 등을 다루기 때문에 단일에너지를 사용하였으며, 전자선 빔 의 반경은 $1 \mathrm{~cm}$ 로 설정하였다. 또한 입사 전자선의 개 수를 한 개로 설정함으로써, 전자 한 개가 입사하였을 때 치료기 헤드를 구성하는 여러 물질들과의 상호작 용에 의해서 생성된 광자수를 추출하였다. 이상의 조 건으로 치료기 헤드를 설정하였으며 전반적으로 본 실험에 부합되는 형태로 독자적인 모델을 모사하였다.

\section{3. 스펙트럼 분석}

타깃을 통과한 후 생성된 광자의 에너지대별 스펙 트럼을 획득하기 위해서, 전자가 타깃을 지난 후 바로 아래 $1 \mathrm{~cm}$ 지점에 반지름이 $1 \mathrm{~cm}$ 인 가상의 검출기를 위치시켰다. 이후 전자선의 에너지 $6 \mathrm{MeV}$ 에서 $24 \mathrm{MeV}$ 까지 $2 \mathrm{MeV}$ 간격으로 실험 대상의 총 10 가지의 에너 지에 대하여 광자의 에너지 스펙트럼을 측정하였다. Tally Specification cards는 F5 Tally를 사용하여 에너지 대별 초당 광자의 수를 구하여 에너지 스펙트럼을 측 정하였다. 세부적으로 F5 Tallys는 가상의 point 또는 ring 형태의 디텍터를 만들어 flux를 측정함으로써 단 위는 particles $/ \mathrm{cm}^{2}$ 로 나타내어 진다. 그리고 모의모사 의 신뢰성 확보를 위해 불확도는 $3 \%$ 이내로 하였으며, 이력수는 $10^{8}$ 개로 설정하였다.

다음 단계로 획득한 스펙트럼을 분석하여 평균 에 너지를 산출하였으며, 텅스텐을 기준으로 광핵 반응 임계 에너지인 $7.41 \mathrm{MeV}$ 이상의 에너지를 가지는 광 자의 개수를 조사하였다.

\section{RESULT AND DISCUSSION}

몬테칼로 계산에 의한 6 24 MV의 에너지대별 스펙 트럼 분포는 Fig. 2와 같이 나타났다. $6 \mathrm{MV}$ 광자선의 경우 평균 에너지는 약 $0.95 \mathrm{MeV}$ 로 산출되었으며 (Table 1), 에너지 분포는 $0.3 \sim 0.5 \mathrm{MeV}$ 구간에서 높은 광자수를 보였다. 텅스텐을 기준으로 광핵 반응에 의 한 중성자 발생의 임계 에너지가 $7.41 \mathrm{MeV}$ 이므로, 광 핵 반응을 일으킬 수 있는 광자 수는 없는 것으로 나 타났다(Table 2).

$8 \mathrm{MV}$ 광자선의 평균 에너지는 약 $1.05 \mathrm{MeV}$ 로 산출 
되었으며(Table 1), 에너지 분포는 $0.4 \sim 0.6 \mathrm{MeV}$ 구간에 서 높은 광자수를 보였다. 광핵 반응을 일으킬 수 있 는 초당 광자 개수는 약 0.0000000023 개로 나타났다 (Table 2). 이 값을 $8 \mathrm{MV}$ 전체에서 검출된 광자 개수에 대해서 $7.41 \mathrm{MeV}$ 이상에서 검출된 광자수를 비교하여 백분율로 나타내면 약 $0.0001 \%$ 를 차지한다.
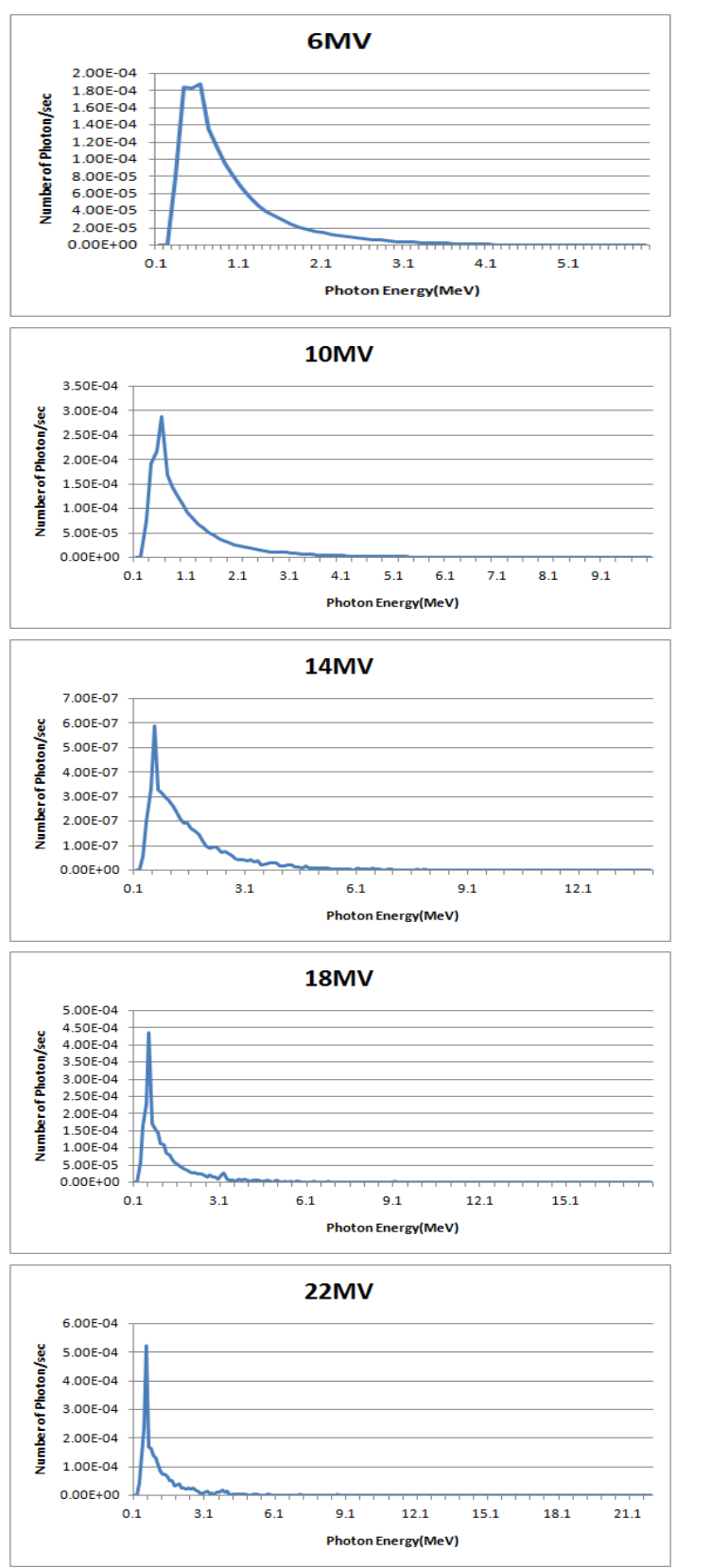

다음 $10 \mathrm{MV}$ 광자선의 평균 에너지는 약 $1.12 \mathrm{MeV}$ 로 나타났다(Table 1). 에너지 분포는 $0.4 \sim 0.6 \mathrm{MeV}$ 구간 에서 높은 광자수를 보였으며, 광핵 반응을 일으킬 수 있는 초당 광자 개수는 약 0.0000006219 개로 나타났다 (Table 2). 이 값은 $10 \mathrm{MV}$ 의 전체 검출 광자 개수에서 약 $0.02 \%$ 를 차지하였다.
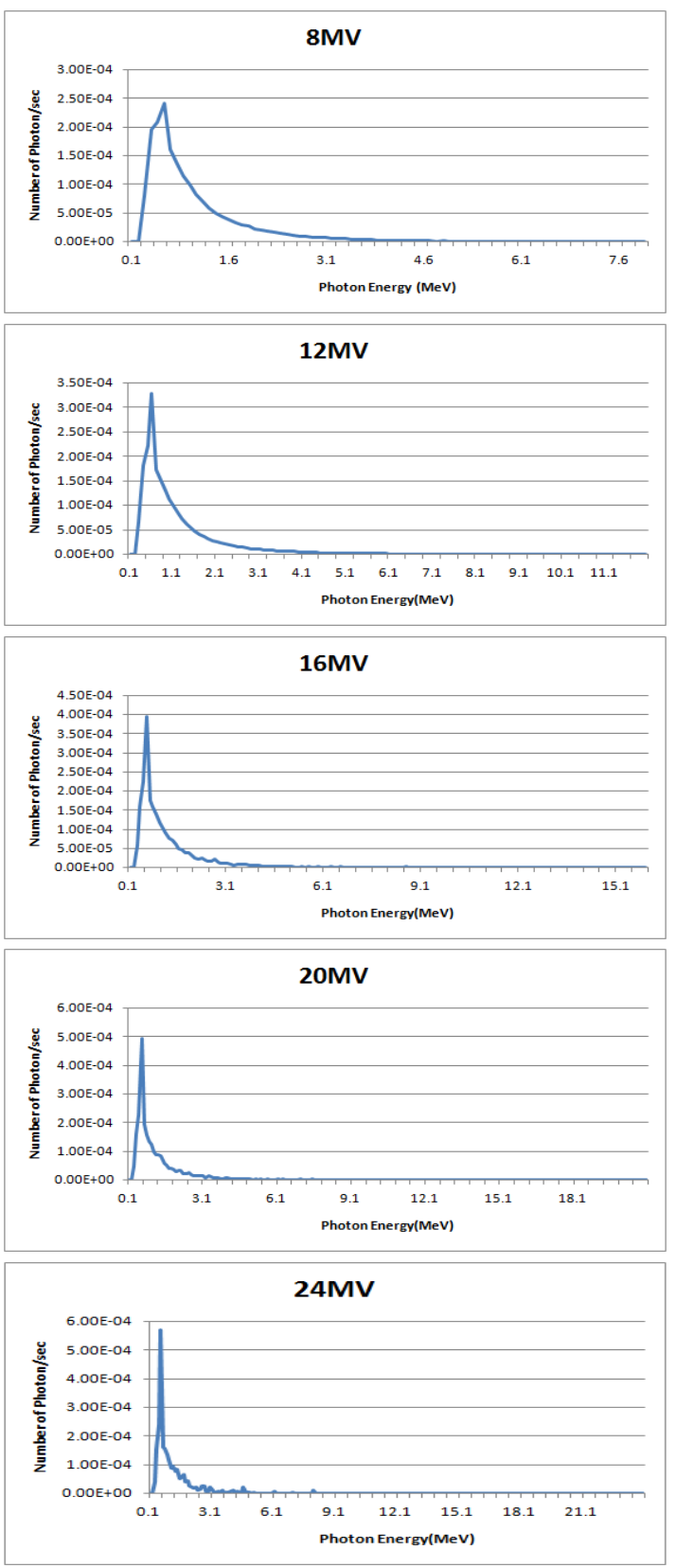

Fig. 2. 6 to $24 \mathrm{MV}$ photon energy spectrum calculated with Monte Carlo at the distance of $1 \mathrm{~cm}$ from the target. 
$12 \mathrm{MV}$ 광자선의 평균 에너지는 약 $1.18 \mathrm{MeV}$ 로 산 출되었으며(Table 1), 높은 광자수를 보인 곳은 0.5 0.6 $\mathrm{MeV}$ 에너지 구간이었다. 광핵 반응을 일으킬 수 있는 초당 광자 개수는 약 0.0000018146 개로 산출되었으며 (Table 2), 이 값은 $12 \mathrm{MV}$ 전체에서 검출된 광자 개수 에 대해서 약 $0.10 \%$ 로 나타났다.

$14 \mathrm{MV}$ 광자선의 평균 에너지는 약 $1.21 \mathrm{MeV}$ 로 산 출되었다(Table 1). 이중 $0.5 \sim 0.7 \mathrm{MeV}$ 구간에서 높은 광 자수를 보였으며, 광핵 반응을 일으킬 수 있는 초당 광자 개수는 약 0.0000045638 개로 나타났다(Table 2). 이 값은 $14 \mathrm{MV}$ 전체 검출 광자 개수에서 약 $0.27 \%$ 를 차지하였다.

다음으로 $16 \mathrm{MV}$ 를 살펴보면 평균 에너지는 약 1.25 $\mathrm{MeV}$ 로 산출되었으며(Table 1), 에너지 분포는 0.4 0.7 $\mathrm{MeV}$ 구간에서 높은 광자수를 보였다. 광핵 반응을 일 으킬 수 있는 초당 광자 개수는 약 0.0000096149 개로 나타났으며(Table 2), $16 \mathrm{MV}$ 전체에서 검출된 광자 개 수에 대해서 백분율로 나타내면 약 $0.22 \%$ 를 차지한다.

$18 \mathrm{MV}$ 의 평균에너지는 약 $1.24 \mathrm{MeV}$ 로 산출되었으 며(Table 1), 0.5 0.7 MeV 구간에서 높은 광자수를 보였 다. 광핵 반응을 일으킬 수 있는 초당 광자 수는 약 0.0000044876 개로 나타났다(Table 2). 이 값은 $18 \mathrm{MV}$ 전체 검출 광자 개수에 대해서 약 $0.35 \%$ 를 차지하는 비율이다.

$20 \mathrm{MV}$ 의 평균 에너지는 약 $1.22 \mathrm{MeV}$ 로 $18 \mathrm{MV}$ 에 비해 조금 낮게 나타났다(Table 1). $0.5 \sim 0.7 \mathrm{MeV}$ 구간에 서 높은 광자수를 보였으며, 광핵 반응을 일으킬 수 있는 초당 광자 수는 약 0.0000083654 개로 나타났다 (Table 2). 마찬가지로 백분율로 나타내면 약 $0.26 \%$ 를 차지한다.

다음 $22 \mathrm{MV}$ 의 평균 에너지는 약 $1.31 \mathrm{MeV}$ 로 산출 되었으며(Table 1), 에너지 분포는 $0.6 \sim 0.7 \mathrm{MeV}$ 구간에 서 높은 광자수를 보였다. 광핵 반응을 일으킬 수 있 는 초당 광자 수는 약 0.0000138799 개로 나타났으며 (Table 2), 이 값을 같은 방식으로 백분율로 계산하면 약 $0.37 \%$ 였다.

마지막으로 $24 \mathrm{MV}$ 광자선의 평균 에너지는 약 1.41 $\mathrm{MeV}$ 로 산출되었으며(Table 1), 0.6 0.7 MeV 구간에서 높은 광자수를 보였다. 광핵 반응을 일으킬 수 있는
초당 광자 수는 약 0.0000151704 개로 나타났다(Table 2). 전체에서 검출된 광자 개수에 대한 백분율은 약 $0.59 \%$ 로 가장 높게 나타났다.

Table 1. The average energy of each energy band (unit MeV)

\begin{tabular}{cc}
\hline Energy & Average energy \\
\hline 6NN & 0.95 \\
\hline 8MN & 1.05 \\
\hline $10 \mathrm{~N}$ & 1.12 \\
\hline $12 \mathrm{~N}$ & 1.18 \\
\hline $14 \mathrm{~N}$ & 1.21 \\
\hline $16 \mathrm{~N}$ & 1.25 \\
\hline $18 \mathrm{~N}$ & 1.24 \\
\hline $20 \mathrm{~N}$ & 1.22 \\
\hline $22 \mathrm{~N}$ & 1.31 \\
\hline $24 \mathrm{~N}$ & 1.41 \\
\hline
\end{tabular}

Table 2. The number of photons per second that more of the threshold energy of photo-nuclear reaction

\begin{tabular}{cc}
\hline Energy & Number of photon/sec \\
\hline 6MN & 0 \\
\hline 8MN & $2.37 \mathrm{E}-09$ \\
\hline $10 \mathrm{~N}$ & $6.22 \mathrm{E}-07$ \\
\hline $12 \mathrm{~W}$ & $1.81 \mathrm{E}-06$ \\
\hline $14 \mathrm{~N}$ & $4.56 \mathrm{E}-06$ \\
\hline $16 \mathrm{~W}$ & $9.61 \mathrm{E}-06$ \\
\hline $18 \mathrm{~W}$ & $4.49 \mathrm{E}-06$ \\
\hline $20 \mathrm{~N}$ & $8.37 \mathrm{E}-06$ \\
\hline $22 \mathrm{~W}$ & $1.39 \mathrm{E}-05$ \\
\hline $24 \mathrm{~N}$ & $1.52 \mathrm{E}-05$ \\
\hline
\end{tabular}

본 연구에서 $6 \mathrm{MV}$ 에서 $24 \mathrm{MV}$ 의 평균에너지를 살 펴보면 약 $0.95 \mathrm{MeV}$ 에서 $1.31 \mathrm{MeV}$ 의 결과값을 보였다. 먼저 $6 \mathrm{MV}$ 광자에 대해 GEANT4 시뮬레이터를 이용 한 타 논문의 경우에는 $6 \mathrm{MV}$ 광자의 평균에너지가 약 $1.67 \mathrm{MeV}$ 로 나타났으며미, $24 \mathrm{MV}$ 광자에 대해 $\mathrm{MCNPX}$ 를 이용하여 중성자의 특성을 연구한 논문에 서는 $24 \mathrm{MV}$ 광자의 평균에너지 값이 약 $4.90 \mathrm{MeV}$ 로 보고하였다 ${ }^{[12]}$. 이렇게 선행 연구와 비교하여 본 연구 에서의 평균 에너지 결과 값이 전체적으로 낮게 나온 이유는 치료기 헤드의 구성 물질, 개개 부품의 물성, 광자 계측 지점 등의 기하학적 조건의 차이로 해석 할 
수 있다.

또한 실험대상의 전체 에너지대에서 광핵 반응을 일으킬 수 있는 광자 개수를 전체 검출 광자 수에 대 해 백분율로 나타낸 결과는 $0 \%$ 에서 약 $0.59 \%$ 로 나타 났는데, 이것은 광자선의 흡수선량에서 중성자가 약 $0.5 \%$ 정도 기여한다는 일반적인 연구결과와 상응하는 결과이다 ${ }^{[2]}$. 하지만 이렇게 계수된 광자가 반드시 광 중성자로 변환되는 것은 아니다. 그러므로 이에 대한 더 정확한 측정을 위해서는 광자 에너지에 따른 중성 자 스펙트럼 분석과 함께 반응 단면적과 중성자 발생 확률 등을 고려한 연구가 필요할 것이며, 더 나아가 중성자는 광자에 비해 산란현상이 높으므로 치료실 차폐벽면과의 상호작용을 더욱 고려하여야 할 것이다. 따라서 방사선 치료실 전체에 대한 전산모사를 통한 추후 실험이 이어져야 할 것이다 ${ }^{[13]}$.

\section{CONCLUSION}

본 연구에서는 $\mathrm{MCNPX}$ 를 사용하여 중성자 연구의 선행 자료로서 활용하기 위해, 실제 임상에서 이용되 고 있는 연속 스펙트럼을 갖는 광자선에 대하여 에너 지대 별로 분석을 함으로써, 평균에너지 산출 및 치료 장치 헤드 구성물질인 텅스텐과 광핵반응을 일으킬 수 있는 $7.41 \mathrm{MeV}$ 이상의 에너지를 가지는 광자 수에 대하여 분석하였다. 그 결과 $8 \mathrm{MV}$ 를 시작으로 $24 \mathrm{MV}$ 에서는 전체 검출 광자수에 비해 $0.59 \%$ 의 비율로서 광 핵 반응을 일으킬 수 있는 광자수가 증가함을 알 수 있었다.

고 에너지의 방사선 치료로 인한 광중성자의 생성 은 방사선 치료 빔을 오염시키는 주요한 원인이다. 이 에 본 연구를 토대로 광중성자 발생에 관한 연구와 함 께 환자의 피폭 선량 산정 및 방사선 치료실의 차폐에 대한 지속적인 연구가 필요할 것이다.

\section{Reference}

[1] Kang SS, Go IH, Kim GJ, Kim SH, Kim YS, Kim YJ et al, " Radiation Therapeutics: 3rd edition," Cheong-gu munhwasa, Korea, 2014.

[2] F. M. KHAN , "The Physics Of Radiation Therapy 4/E", Lippincott Williams \& Wilkins, 2009.
[3] W.L. Huang , Q.F. Li , Y.Z. Lin, "Calculation of photoneutrons produced in the targets of electron linear accelerators radiography and radiotherapy applications", Nuclear Instruments and Methods in Physics Raesearch B, Vol. 229, Issues 3, pp.339-347, 2005.

[4] Kim KT, Kang SS, Noh SC, Jung BJ, Cho CH, Heo YJ, Park JK, "Absorbed Spectrum Comparison of Lead and Tungsten in Continuous X-ray Energy using Monte Carlo Simulation", Journal of the Korean Society of Radiology, Vol. 6, No. 6, pp.483-487, 2012.

[5] Pelowitz, Denise B., "MCNPX ${ }^{\mathrm{TM}-}$ User's manual version 2.5.0", Los Alamos National Laboratory, 2005.

[6] Kim YH, "Dose Distribution Calculation Using MCNPX code in the Gamma-ray Irradiation Cell", Department of Nuclear \& Energy Engineering Graduate School, Cheju National University, 2008.

[7] Ma CM, Li JS, Pawlicki T, Jiang SB, Deng J, Lee MC, Koumrian T, Luxton M and Brain S. "A Monte Carlo dose calculation tool for radiotherapy treatment planning", Phys. Med. Biol., Vol. 47, No.10, pp.1671-1689, 2002.

[8] Keall PJ, Siebers JV, Arnfield M, Kim JO and Mohan R "Monte Carlo dose calculations for dynamic IMRT treatments", Phys. Med. Biol., Vol. 46, No. 4, pp.929-941, 2001.

[9] Kang SK, Ahn SH, Kim CY, " A Study on Photon Dose Calculation in 6 MV Linear Accelerator Based on Monte Carlo Method", Journal of Radiological Science and Technology, Vol. 34, No. 1, pp.43-50, 2011.

[10] Kawrakow I. "Accurate condensed history Monte Carlo simulation of electron transport. I. EGSnrc, the new EGS4 version", Med. Phys., Vol.27, No. 3, pp.485-498, 2000.

[11] Sheikh-Bagheri, D., Rogers, D. W. O., "Monte Carlo calculation of nine megavoltage photon beam spectra using the BEAM code", Medical physics, Vol. 29, No. 3, pp.391-402, 2002.

[12] Lee JO, Jeong DH, Kang JK, "Neutron Generation from a 24 MV Medical Linac", Korean J Med Phys., Vol. 16, No. 2, pp.97-103, 2005.

[13] Clifford Dugal, B.Eng., "Application of Monte Carlo to Linac Bunker Shielding Design", Ottawa Carleton Institute for Physics Department of Physics, Carleton University, 2006. 